\title{
Adult hepatocellular carcinoma
}

INSERM

\section{Source}

INSERM. (1999). Orphanet: an online rare disease and orphan drug data base. Adult hepatocellular carcinoma. ORPHA:210159

Adult hepatocellular carcinoma is the most common primary liver cancer of adulthood. Derived from well-differentiated hepatocytes, it often develops from chronic liver cirrhosis which is most often due to hepatitis B and C virus or alcohol abuse. Symptoms are hepatic mass, abdominal pain and, in advanced stages, jaundice, cachexia and liver failure. 